\title{
Investigating Social Media Influences on Consumer's Behaviors Purchasing Sports Apparel
}

\author{
Dr. Yahya Manna \\ Jazan University, PO box 114, Jazan 45142, KSA
}

\begin{abstract}
Social media is the most prevalent means of communication among young people today; consequently, social media provides an ideal platform for promoting brands of products and services, influencing consumers' purchasing decisions, and increasing the desire to use products offered. Companies selling sports apparel (like Puma and Adidas) have approached marketing through social media, investigating social media's effect on consumer behavior and choice of sports apparel in Saudi Arabia. To achieve the objectives of this research, and to answer the questions posed a descriptive analytical approach was used, and a survey (questionnaire and interview) tools were distributed to a sample of consumers and e-consumers of sportswear (comparative between Puma and Adidas). To test the effects of age, gender, living area, and the respondents' educational level on customers' preference for Puma and Adidas (t-shirts and shoes), the researcher investigated whether preferences for Puma and Adidas sportswear brands ( $\mathrm{t}$-shirts and shoes) are affected by the age, genders, living area and educational level of the respondents.
\end{abstract}

Keywords: consumers, behavior, influenced, social media, sports apparel, sportswear.

DOI: $10.7176 / \mathrm{EJBM} / 11-26-07$

Publication date:September $30^{\text {th }} 2019$

\section{Introduction}

Recent few years have witnessed a significant investment by companies in marketing through social media as a way to advertise products and services, such as: Twitter, Snapchat, Instagram, Facebook, and LinkedIn. These are new platforms that allow users to communicate with one another, and identify and engage with brands. These channels promote content through texting, images, audio and video, complementing other marketing strategies to attract new consumers.

There is little doubt that research into consumer behavior is challenging, but it is vital for policy making institutions in general and marketing managers in particular. The stance of the consumer as understood in the context of modern marketing has become a primary focus of the marketing process. Successful social media marketing relies on developing a clear understanding of consumers' behavior, and an awareness of their needs and desires with regard to time, place and quality preferences (Castro, 2006).

Consumer behavior is influenced by several socio-economic, psychological and cultural factors, etc. The study and analysis of consumer behavior crucial for devising marketing activities, such as those that sportswear companies are engaged in. Such activities have emerged as a result of developments in the external environment arising from increased competition and the expansion of alternatives available to the consumer as well as shifts in needs (Makarewicz, 2013). Sportswear companies strive for excellence in their products, both in terms of quality and price, or method of advertising or distribution, in accordance with consumers financial capabilities (Alsbiei, 2015).

\subsection{Research problem}

Social media has become an important communication tool used by people to connect with others when communicating about organizations. People use social media to share their experiences, opinions, information, advice, warnings, or other areas of interest to their friends or contacts. This information serves as a useful resource, which might then affect the consumer's decision-making process. The majority of studies have shown that people use information gathered on social media as guidelines for future procurement (Baruah, 2012). Social media is also used as an advertising tool by marketers, and marketers take this into account when developing a marketing strategy through this channel to enable them to win more customers. Sports clothing is one of the most important sectors experiencing frequent changes over short periods, Social media is the most convenient and cost-effective way to introduce and promote new products. Therefore, the current research has been prepared to examine social media's influences on consumer behavior when purchasing sports apparel.

\subsection{The aim and significance of the research}

The study of human behavior has been of great importance since ancient times, and it is important to try to identify it and the factors that affect it. This is because the behavior of individuals is affected by many factors, and it varies accordingly. There is a clear difference in the behavior of individuals, based on countries, regions, races, customs, traditions, laws, customs, civilizations and other factors. The current research focuses on the factors informing 
customers' choices.

\subsection{Research question and objectives}

The current research problem answers the following main questions:

* What is the extent of social media influences on consumer behavior regarding sportswear? A number of sub-questions emerge from this as follows:

- What is the influence of social media?

- What determines consumer behavior?

- How do consumers become interested in following products on social media?

- To what extent are sportswear companies interested in marketing their products through social media?

Here are the main objectives the current research will seek to achieve:

- Identify the influences of social media.

- Highlight consumer behavior.

- Reveal the extent to which consumers are interested in following products through social media.

- Highlight the interest of sports clothing companies in marketing their products through social media.

\section{Literature review}

This part of the research provides a theoretical framework for social media's influence on consumer's behaviors with regard to Sports Apparel:

\subsection{Consumer's behavior of Sports Apparel}

Behavior is generally defined as how organisms behave in response to environmental conditions when engaged in an activity that is intended to modify or alter these conditions so they become suitable for their survival.

Sammut et al. (2015) assumed that human behavior is a product of community and global installation. Humans categorize and adjust to their environment. Stabilization of behavior like motivations, favorites, or attitudes happens in psychological, physical, and institutional stages (Allwood, 2010).

The physical layer requires physical objects that persons can adopt to embark on actions. The environment controls what individuals can do. On the other hand, social exemplification happens at the psychological stage when persons initiate activities that depend on mind and motive. The sensory-motor feature plays a serious role in safeguarding the activities that occur.

According to Sammut et al. (2015), institutional features define common conventions that inform cooperation. Moreover, interactive dynamic relationships among social exercise, social information, and joint identities highlight attitudes. Individuals cannot be divided from their favorite things, but instead are prone to grounding their choices on their understanding of the physical, social and psychological environment.

Consumer behavior encompasses two concepts: behavior and consumerism. Accordingly, consumer behavior can be defined as the mental and physical activity of an individual, involving the assessment of goods and services, in order to obtain the best for use (Vainikka, 2015).

The study of consumer behavior addresses the activities and behaviors of the consumer that are directly related to satisfying his needs and desires, and which govern the consumption process. From this perspective, consumer behavior can be defined as: "The group of actions issued by individuals, associated with the purchase and use of economic goods and services, including the decision-making process that precedes and determines these actions" (Lautiainen, 2015).

Sportswear includes footwear and apparel designed for use when participating in sports; it can also be worn as casual clothes or shoes for day-to-day activities (Hoyer and MacIness, 2004). According to Euromonitor International (2014), since 2010, sportswear consumption has been gradually increasing by an average of 4.5 per cent per annum, with 2014 showing an increase of 7 per cent. The increase in demand for sportswear brands has attracted several new entrants into the market, such as casual-end retailers, generating stiff competition in the currently crowded market for sportswear brands. Lululemon Athletica and Armour are new sportswear players, whose market share has grown rapidly as a result of their focus on niche markets; for example, yoga-inspired sportswear and performance apparel. Euromonitor International (2014) also indicated that by 2017 the global expansion in the sportswear sector will generate an additional $\$ 60$ billion in new sales. With figures such as these, sportswear brands are required to strategize in order to reap benefits and profits through increased sales and the growing demand for sportswear brands.

According to Milano and Chelladurai (2011), in 2005, consumer expenses on sports clothing and athletic shoes in the United States were estimated as between US\$40 billion and US\$16 billion (Milano \& Chelladurai, 2011). However, by 2011 the global sports clothing market had reached approximately US \$ 132 billion (Statista, 2015). The growth in demand for sports clothing reflects an increase in sports participation among the general 
population, and greater acceptance of sports attire as everyday wear. In addition to athletes who buy sports clothes to enhance their performance when engaging in sports activities, athletes and other consumers also buy sportswear for use outside the sporting arena (Chew \& Leng, 2016).

Not all consumer purchase decisions are alike, and the amount of effort put into the decision making process varies. When the decision-making process is almost automatic, snap judgments can be made with minimal searches for information. Consumer's behaviors towards a specific product or commodity differ. Some automatic behaviors can arise involving little risk and low participation. However, some behaviors require a lot of time and information searches. Thus, consumer behavior involves four main types, as illustrated in Figure 1 (Kardes, Cline, \& Cline, 2011).

\begin{tabular}{|c|c|c|}
\cline { 2 - 3 } & \multicolumn{1}{c}{ High involvement } & \multicolumn{1}{c}{ Low involvement } \\
\cline { 2 - 3 } $\begin{array}{c}\text { Significant differences } \\
\text { between brands }\end{array}$ & $\begin{array}{c}\text { Complex buying } \\
\text { behavior }\end{array}$ & $\begin{array}{c}\text { Variety-seeking buying } \\
\text { behavior }\end{array}$ \\
\cline { 2 - 3 } $\begin{array}{c}\text { Few differences } \\
\text { between brands }\end{array}$ & $\begin{array}{c}\text { Dissonance-reducing } \\
\text { buying behavior }\end{array}$ & $\begin{array}{c}\text { Habitual buying } \\
\text { behavior }\end{array}$ \\
\cline { 2 - 3 } & &
\end{tabular}

Figure 1: types of consumer behavior. (Kardes, Cline, \& Cline, 2011)

\subsection{Social media influences}

There are multiple definitions of social media, and these vary from one researcher to another. According to Chauhan and Pillai (2013), social media is defined as an electronic system that allows Internet users to create their own pages and connect them via an electronic social system to other members who share the same interests and hobbies, as a means to educate and inform others about information, products, services (Chauhan \& Pillai, 2013). Social media can be defined as a system of electronic networks that permit subscribers to create their own pages, and then connect them through a social e-system to those of other members who share the same interests and hobbies (Taprial \& Kanwar, 2012).

Social media applications support communication and interaction via electronic means. Some individuals use the concept of mass media to describe the various types of cultural phenomena that involve communication, not just communication techniques (Valentini \& Kruckeberg, 2011). For example, people often use the term social media to discuss the content that users provide when writing, publishing, or sharing using electronic data. It is noteworthy that the majority of social media sites are electronic and give users minimum opportunity to communicate and interact with each other using computers, smartphones, the Internet, and other social networks such as Facebook, Twitter, Paint Rest (Mazurek \& Tkaczyk, 2016).

Buyer intentions indicate whether customers want to purchase specific services or products from online group purchase sites (Yang and Mao, 2014), and these can be oriented towards specific products.

\subsection{Social media influences on consumers behavior of Sports Apparel}

Social media influences consumers by engaging them in the business world, and assisting marketers to create a novel set of tools to interact with consumers and integrate them into brands using innovative electronic methods (Prasath \& Yoganathen, 2018).

Consumers' purchasing decisions might also be effected by social influence, as people review the perceptions and judgments of others about products when making their own decisions. Thus, the more uncertain a person is about a product, the greater the likelihood that he or she will be affected by social media (Chew \& Leng, 2016).

Social influence can be classified as either normative or informational. Informational social influence refers to receiving data acquired from another person as proof of reality. When consumers seek to create an informed decision, they view the opinions of others or the use of products as reliable evidence of a consumable items' qualities or features. Intrinsically, a purchase decision is influenced by the opinions of others (Yayli \& Bayram, 2012).

The key reason why consumers purchase what they do is often deeply rooted in their subconscious. Therefore, typically, consumers do not fully understand or know what affects their product or brand purchase decisions, as 99 per cent of these are emotional, and occur in the unconscious mind; i.e. without their awareness (Sokolowski, 2011).

Social media effectively influences consumer choices and behavior. Companies create social networking pages to disseminate information, videos, images and text as a way to describe their products and services. Consumers can access these pages, obtain information, communicate with their sponsors, purchase products, join a group, or view new developments in the company's products. Consumers and companies can think about products or company related issues on these pages (Tilman, 2012). 
There are three theories that support this research, and which aim to highlight consumers' purchasing behavior in regard to brands of sportswear (T-shirts and shoes). These theories consist of social exemplification, behavioral purpose, and online purchasing (Anfara and Mertz, 2014). The three theories are created and designated in-depth as a way to provide descriptions, expectations, and cleverness about the phenomena under study. The primary goal is to design a realistic model of consumers' and e-consumers' behaviors towards brands of sportswear like Adidas and Puma. Despite theoretical generalization, the notes accompanying the framework confirm the creation of existing and clear ideas about the phenomenon under analysis (Ravitch and Riggan, 2012). The connections and comparative examination conducted in the project are not based on personal instincts or assumptions, but rather on theories of social exemplification, behavioral attention, and online purchasing, as well as prior research.

\section{Social representation theory}

Social representation theory reflects behavior through a process of reconstruction. Frequently procedures happen from a young age, in schools, families, organizations, and communities. People are able to improve certain methods of conceptualizing things or states directed through the situations around them (Hamilton et al., 2014). The exemplifications set detail three groups of features, all of which define behavior and consequently convictions about things (Gaol, Kadry, Taylor and Li, 2014). The institute is the first feature whereby components of social exemplification cooperate with each other. These components comprise opinions, faith, and information, which could be either equivalent or incompatible. On the other hand, a common feature is the second peculiarity informing exemplification. Participants in the same social set rely on information managed about a certain thing to establish methodical attitudes about it. Moreover, joint creation is the third structural component, although individuals rely on revelation to establish mass connections and improve opinions and information (Khanlari, 2015). The theory of social representation observes behavior that can be considered as socially beneficial.

\section{Online buying theory}

Online shopping behavior can arise from a number of impulsive purchasing triggers. Customers may respond to incentives affirming their intention to make a purchase. According to Lo, Lin and Hsu (2016), compulsive buying in bricks-and-mortar settings varies from online behavior. Conversely, growing demand for an effective and rapid purchasing process adds to customers' impulsive purchasing in ecommerce settings (Wan, 2009). The motive informing unsolicited consumer shopping behavior is sales campaigning. Confidence, price comparison, and shopping opportunities precipitate behavior, but there is also a necessity for sellers to finalize e-commerce purchases efficiently. Al-Debei, Akroush, and Ashouri (2015) discuss how sellers' capability to impact online purchases emanates from their efforts to exploit word of mouth electronically (eWOM). They realize welfare and web features serve to promote consumers' affirmative attitudes towards online shopping. Wan (2009) notes that the theory of online purchasing emphasizes the utilization of suitability between consumers, which then becomes a foundation for effective sales.

\section{Behavioral intention}

Behavioral intention theory includes foreseeable choices made between consumers (Carrington, Neville and Whitwell, 2014). The behavioral intention of consumers and e-consumers may vary depending on their implementation of social media, social class, and social exemplification. The intention to purchase a particular product stems from pre-existing attitudes in the decision-making procedure. The basic component of the theory is that it is an expressed essential, developed via consumers to generate or realize a specific result. Comprehensibly, Carrington, Neville and Whitwell (2014) noted that consumers are involved in a logical procedure, which includes appropriate assessment of target products. Logical performer's methods that serve as a foundation for exploitation are in agreement with their best welfare options. The intention to use logical action to inform the decision-making procedure needs specificity. Consumers embrace certain actions when they think about outcomes (Hong and Cho, 2011). Conversely, consumers can vary their opinions and choose an act devised based on information they consume in their environment, comprised of social sets or social media networks.

\subsection{Research methodology}

To achieve the objectives of this research and answer the questions attendant in Investigating social media influences on consumer's behaviors of Sports Apparel in Saudi Arabia through conducting a comparative study between the perceptions of consumers and E-consumers, a descriptive analytical approach was used (both qualitative and quantitative methods), and a questionnaire tool was distributed to a sample of users of social media interested in following developments in the field of sportswear.

\subsection{Hypothesis.}

The researcher developed a set of hypotheses to be tested through the current research:

H1: There is a positive relationship between Social Representation and Attitude at significance level $\alpha=0.05$. 
H2: There is a positive relationship between Social Class and Attitude at significance level $\alpha=0.05$.

H3: There is a positive relationship between Social Media and Attitude at significance level $\alpha=0.05$.

H4: There is a positive relationship between Social Representation and Preference at significance level $\alpha=0.05$.

H5: There is a positive relationship between Social Class and Preference at significance level $\alpha=0.05$.

\subsection{Discussion and Results}

Determining the validity of the questionnaire structure was the second test undertaken. This test determined the validity of each section within the questionnaire as a way to affirm its validity. The test measured the correlation coefficient between one segment and all the other sections of the questionnaire, at a similar level to the Likert scale. Table 1 illustrates that significance values are lower than 0.01 . Hence, the correlation coefficients of the questionnaire segments are significant at $\alpha=0.01$. Thus, each segment is valid because the significance determined they achieved what they were intended to in the study.

Table 1: structural validity of the questionnaire.

\begin{tabular}{|c|l|c|c|c|c|}
\hline \multirow{2}{*}{ No. } & \multicolumn{2}{|c|}{ Section } & \multicolumn{2}{|c|}{ Adidas Sportswear } & \multicolumn{2}{c|}{ Puma Sportswear } \\
\cline { 3 - 6 } & $\begin{array}{c}\text { Pearson } \\
\text { Correlation } \\
\text { Coefficient }\end{array}$ & $\begin{array}{c}\text { P- } \\
\text { Value }\end{array}$ & $\begin{array}{c}\text { Pearson } \\
\text { Correlation } \\
\text { Coefficient }\end{array}$ & $\begin{array}{c}\text { P- } \\
\text { Value }\end{array}$ \\
\hline 1 & Social Representation & 0.608 & 0.000 & 0.615 & 0.000 \\
\hline 2 & $\begin{array}{l}\text { Attitude Preference and } \\
\text { Behaviour of Consumers and E- } \\
\text { Consumers }\end{array}$ & 0.716 & 0.000 & 0.863 & 0.000 \\
\hline
\end{tabular}

The half-split method involves determining the Pearson correlation coefficients between the means of even and odd ranked queries in each questionnaire segment. The Spearman-Brown correlation coefficient facilitated the correction of the Pearson correlation coefficient. The following equation is used in the computation of corrected correlation or consistency correlations. The consistency coefficient $=2 r /(r+1)$, where $r$ is the Pearson correlation coefficient in the normal range of the corrected correlation coefficient $2 \mathrm{r} /(\mathrm{r}+1)$, which is between 0.0 and +1.0 Table 2 shows the overarching reliability of each item is equal to $0.841,0.859$ for Adidas sportswear and Puma sportswear respectively, and the significance $(\alpha)$ is less than 0.05 , so all the modified correlation coefficients are significant at $\alpha=0.05$. Hence, guided by the Half-Split technique, the corrections made are reliable.

Table 2: Alf-split technique.

\begin{tabular}{|c|c|c|c|c|c|}
\hline \multirow[b]{2}{*}{ No. } & \multirow[b]{2}{*}{ Section } & \multicolumn{2}{|c|}{ Adidas Sportswear } & \multicolumn{2}{|c|}{ Puma Sportswear } \\
\hline & & $\begin{array}{c}\text { Person- } \\
\text { Correlation }\end{array}$ & $\begin{array}{c}\text { Spearman- } \\
\text { Brown } \\
\text { Coefficient }\end{array}$ & $\begin{array}{c}\text { Person- } \\
\text { Correlation }\end{array}$ & $\begin{array}{c}\text { Spearman- } \\
\text { Brown } \\
\text { Coefficient }\end{array}$ \\
\hline 1 & Social Representation & 0.712 & 0.831 & 0.817 & 0.899 \\
\hline 2 & $\begin{array}{l}\text { Attitude Preference and } \\
\text { Behaviour of Consumers } \\
\text { And E- Consumers }\end{array}$ & 0.735 & 0.848 & 0.706 & 0.827 \\
\hline 3 & All Items & 0.725 & 0.841 & 0.753 & 0.859 \\
\hline
\end{tabular}

Cronbach's Coefficient Alpha is a method of measuring the reliability of a questionnaire between the segments and mean of all segments in a questionnaire. The standard range of Cronbach's Coefficient Alpha value is between 0.0 and +1.0 while the higher values illustrate a higher marker of internal consistency. Table 3 below calculates Cronbach's Coefficient Alpha. This table shows that the general reliability of all segments is equal to 0.856 and 0.879 for Adidas sportswear and Puma sportswear respectively. The range here is high, which implies the questionnaire had high reliability. 
Table 3: Cronbach's Coefficient Alpha.

\begin{tabular}{|c|l|c|c|}
\hline \multirow{2}{*}{ No. } & \multicolumn{1}{|c|}{ Section } & \multicolumn{1}{c|}{ Adidas } & \multicolumn{2}{c|}{ Puma } \\
& & sportswear & sportswear \\
\cline { 3 - 4 } & & \multicolumn{2}{|c|}{ Cronbach's Alpha } \\
\hline 1 & Social representation & 0.843 & 0.901 \\
\hline 2 & Attitude preference and behaviour of consumers and & 0.852 & 0.851 \\
\hline 3 & E- consumers & & \\
\hline
\end{tabular}

\subsection{Finding and hypotheses test}

The aim of this section is to validate the proposed research model and test associated hypotheses using an appropriate statistical approach. The response to the first question in the Adidas and Puma questionnaire (Have you ever heard of the brand Adidas or Puma?), given in Table 4, shows that all the research participants had heard of Adidas and Puma.

Table 4: knowledge of the Adidas brand and Puma brand.

\begin{tabular}{|c|c|c|c|c|}
\hline $\begin{array}{c}\text { Have you ever } \\
\text { heard of the brand } \\
\text { Adidas? }\end{array}$ & \multicolumn{2}{|c|}{ Brand Adidas } & \multicolumn{2}{c|}{ Brand Puma } \\
\cline { 2 - 5 } & Frequency & Percentages & Frequency & Percentages \\
\hline Yes & 561 & 100.0 & 547 & 100.0 \\
\hline No & 0 & 0.0 & 0 & 0.0 \\
\hline Total & $\mathbf{5 6 1}$ & $\mathbf{1 0 0 . 0}$ & $\mathbf{5 4 7}$ & $\mathbf{1 0 0 . 0}$ \\
\hline
\end{tabular}

We used a one-sample t-test to identify the opinions of the respondents concerning the Adidas sportswear brand (t-shirt and shoes), and the results are shown in Table 5 as follows. In general, the results for all the items in the field show Table 5, that the average mean equals 3.00 and 3.09 for t-shirts and shoes respectively, and the weighted mean is equal to $75.08 \%$ and $77.24 \%$ for $\mathrm{t}$-shirts and shoes respectively. The value of the t-test is equal to 31.47 and 36.15 for t-shirts and shoes respectively, which is greater than the critical value of 1.98 . The p-value is equal to 0.000 and 0.000 for t-shirts and shoes respectively, which is less than 0.05 . This means the Adidas sportswear brand affects consumers and e-consumers of Adidas (t-shirts and shoes) in Saudi Arabia at a significance level of $\alpha=0.05$

Table 5: Social Representation (SR) of Adidas brand.

\begin{tabular}{|c|c|c|c|c|c|c|c|c|c|c|}
\hline \multirow[b]{2}{*}{ Items } & \multicolumn{5}{|c|}{ t-shirts } & \multicolumn{5}{|c|}{ Shoes } \\
\hline & 怘 & 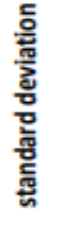 & 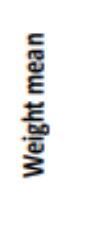 & $\frac{\mathrm{g}}{\mathrm{g}}$ & $\frac{\stackrel{y}{\frac{\pi}{n}}}{\frac{d}{d}}$ & 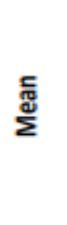 & 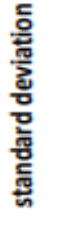 & 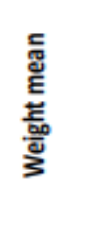 & $\frac{\mathrm{g}}{\mathrm{g}}$ & $\frac{\text { 믈 }}{3}$ \\
\hline \multicolumn{11}{|c|}{ According to you, is Adidas sportswear always and in all cases: } \\
\hline All items of (SR) & 3.00 & 0.27 & 75.08 & 31.47 & 0.00 & 3.09 & 0.27 & 77.24 & 36.15 & 0.00 \\
\hline
\end{tabular}

The one-sample t-test was used to collate opinion of respondents concerning Puma. The results for all the items in the field shown in Table 6 reveal that, the average mean equals 2.23and 2.25for Puma t-shirts and shoes respectively and the weighted mean equals $55.66 \%$ and $56.19 \%$ for $\mathrm{t}$-shirts and shoes respectively. The value of the t-test is equal to 22.83 and 18.83 for t-shirts and shoes respectively, which is greater than the critical value of 1.98. The p-value equals 0.000 and 0.000 for t-shirts and shoes respectively, which is less than 0.05 . This means the Puma sportswear brand moderately affects consumers and e-consumers' views regarding Puma (t-shirts and shoes) in Saudi Arabia at significance level $\alpha=0.05$. 
Table 6: Social Representation (SR) of puma brand.

\begin{tabular}{|c|c|c|c|c|c|c|c|c|c|c|}
\hline \multirow[b]{2}{*}{ Items } & \multicolumn{5}{|c|}{ t-shirts } & \multicolumn{5}{|c|}{ Shoes } \\
\hline & 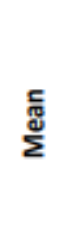 & 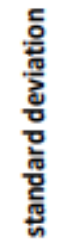 & 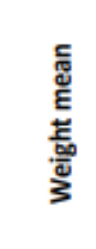 & $\frac{\mathrm{g}}{\mathrm{J}}$ & $\frac{d}{\frac{d}{3}}$ & 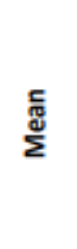 & 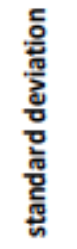 & 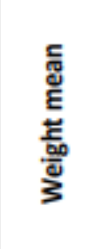 & $\frac{\mathrm{g}}{\mathrm{J}}$ & $\frac{\stackrel{0}{3}}{3}$ \\
\hline \multicolumn{11}{|c|}{ According to you, is Adidas sportswear always and in all cases: } \\
\hline All items of (SR) & 2.23 & 0.20 & 55.66 & -22.83 & 0.00 & 2.25 & 0.22 & 56.19 & -18.83 & 0.00 \\
\hline
\end{tabular}

1. Consumers and e-consumers showed a largely positive attitude towards the Adidas sportswear brand (tshirts and shoes).

As mentioned a one-sample t-test was used to assess the opinion of the respondents about the attitude, preference and behavior of consumers and e-consumers towards Adidas, and the results are shown in Table 7. All items in the field show the average mean equals 3.15 and 3.11 for t-shirts and shoes respectively, and the weighted mean equals $78.70 \%$ and $77.82 \%$ for $t$-shirts and shoes respectively. The value of the t-test equals 15.93 and 15.68 for t-shirts and shoes respectively, which is greater than the critical value of 1.98 . The $p$-value is equal to 0.000 and 0.000 for $t$-shirts and shoes respectively, which is less than 0.05 . This means the attitude of consumers and e-consumers towards Adidas t-shirts and shoes is good at a significance level $\alpha=0.05$.

Table 7: Attitude of consumers and E- consumers towards Adidas (t-shirts and shoes).

\begin{tabular}{|c|c|c|c|c|c|c|c|c|c|c|}
\hline & \multicolumn{5}{|c|}{ T-shirts } & \multicolumn{5}{|c|}{ Shoes } \\
\hline Items & 胥 & 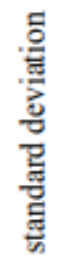 & 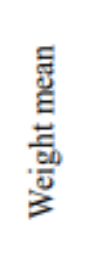 & 总 & 气 & $\underset{\text { J्J }}{\text { J }}$ & 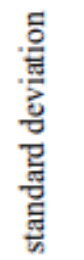 & 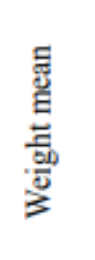 & 茎 & 旁 \\
\hline Attitude (all items) & 3.15 & 0.69 & 78.70 & 15.93 & 0.00 & 3.11 & 0.65 & 77.82 & 15.68 & 0.00 \\
\hline
\end{tabular}

2. Consumers and e-consumers showed a negative attitude towards the Puma sportswear brand (t-shirts and shoes).

We also employed a one-sample t-test to evaluate the opinions of the respondents regarding the attitude, preferences and behaviors of consumers and e-consumers towards the Puma sportswear brand ( $\mathrm{t}$-shirts and shoes) and the results shown in Table 8. The results for all items in the field show the average mean equals 2.02 and 1.97 for t-shirts and shoes respectively and the weighted mean equals $50.51 \%$ and $49.14 \%$ for t-shirts and shoes respectively. The value of the t-test equals 12.83 and 15.27 for t-shirts and shoes respectively, which is greater than the critical value of 1.98 . The p-value equals 0.000 and 0.000 for $t-$ shirts and shoes respectively, which is less than 0.05 . This means the attitude of consumers and econsumers towards Puma (t-shirts and shoes) is negative at the significance level $\alpha=0.05$.

Table 8: Attitude of consumers and E- consumers towards Puma (t-shirts and shoes).

\begin{tabular}{|c|c|c|c|c|c|c|c|c|c|c|}
\hline & \multicolumn{5}{|c|}{ T-shirts } & \multicolumn{5}{|c|}{ Shoes } \\
\hline Items & $\underset{\text { J }}{\text { J }}$ & 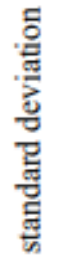 & 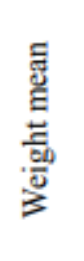 & 总 & 总 & $\underset{\text { हี }}{\stackrel{\Xi}{\Sigma}}$ & 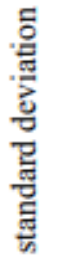 & 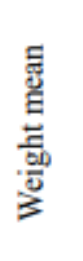 & 总 & 号 \\
\hline Attitude (all items) & 2.02 & 0.62 & 50.51 & -12.83 & 0.00 & 1.97 & 0.58 & 49.14 & -15.27 & 0.00 \\
\hline
\end{tabular}


3. The extent of customers' preference for the Adidas sportswear brand ( $\mathrm{t}$-shirts and shoes) is affected by the age, gender, living area and educational level of the respondents. To test the effects from the age, gender, living area and the educational level of the respondents on the extent of customers' preference for Adidas, we employed a chi-square test. The result in Table 9 shows that age and education level only affected customers' preference for Adidas, since the p-value equal 0.018 and 0.000 for age and educational level respectively.

Table 9: Chi-square test Adidas brand t-shirts and shoes.

\begin{tabular}{|c|c|c|c|}
\hline Variable & Chi-square & p-value & Results \\
\hline Age & 55.985 & 0.018 & Affected \\
\hline Gender & 5.957 & 0.744 & Not affected \\
\hline Living area & 11.33 & 0.254 & Not affected \\
\hline Educational level & 89.259 & 0.000 & Affected \\
\hline
\end{tabular}

4. The extent of customers' preferences for the Puma sportswear brand (t-shirts and shoes) is affected by the age, gender, living area and educational level of the respondents. To test for the effect of age, gender, living area and educational level of the respondents on customers' preferences for Puma t-shirts and shoes, we used a chi-square test. The results in Table 10 show that age and education level only affected the extent of customers' preferences for the Puma sportswear brand ( $t$-shirt and shoes), since the p-values equal 0.018 and 0.000 for age and educational level respectively.

Table 10: Chi-square test Puma brand (t-shirts and shoes).

\begin{tabular}{|l|l|l|l|}
\hline Variable & Chi-square & p-value & Results \\
\hline Age & 143.002 & 0.000 & Affected \\
\hline Gender & 20.48 & 0.015 & Affected \\
\hline Living area & 8.244 & 0.510 & Not affected \\
\hline Educational level & 101.984 & 0.000 & Affected \\
\hline
\end{tabular}

\section{Conclusion}

The current search was prepared to investigate social media influences on consumer's behavior relative to sports apparel in Saudi Arabia. A descriptive analytical approach was designed to review previous studies and research relating to the subject of the research. In addition the survey tools were distributed to a sample of consumers and e-consumers of sportswear brands (comparative between Puma and Adidas). It has further been shown that the modes of social communication help consumers who are athletes and non-athletes interested in wearing sports clothing select brands and models suitable for them at appropriate prices. Thus, social media influences consumer behavior. Some important aspects of the analysis included consumers determining the frequency of Internet purchases. A good results perspective included determining the behavior of consumers in accordance with demographics, encompassing age, gender, living area, and education level.

Based on the survey tools prepared by the researcher, and based on the views of the participants using this tool, the researcher reached the following conclusions:

- The behavior of consumers towards a particular product of sportswear is influenced by data disseminated via social media.

- Consumer purchasing behavior is influenced by feedbacks for products published on social media by former consumers.

- The buying behavior of consumers interested in buying sports apparel is influenced by the electronic content of marketers on social media.

- Some consumer do not trust the digital content of the social media provided by marketers to describe the sportswear they offer.

- Some consumers feel comfortable with sports clothing companies that offer digital content to describe their products on social media.

- The digital content provided by companies on social media websites intended to describe their sportswear helps generate consumer purchasing desire.

In light of the above, the researcher recommends the following:

- The importance of adopting sports apparel companies for social communication in their work allows them to focus their efforts to increase the effectiveness of content added on social media.

- Sports clothing companies need to pay attention to assigning teams responsible for follow-up, 
development and updating of content on social media, to provide feedback to users about their contents and products.

- Encourage users of social media to adhere to the credibility of information about products and services published on their personal accounts.

- Informing consumers about the incorrectness of some information and the information that they find on social media.

\section{References}

Al-Debei, M., Akroush, M., and Ashouri, M. (2015). Consumer attitudes towards online shopping. Internet Research, 25(5), 707-733. http://dx.doi.org/10.1108/ intr-05-2014-0146

Allwood, C. (2010). Decision making. Dordrecht: Kluwer.

Alsbiei, O. A. (2015). ADIDAS Group Strategy Analysis. University of Sharjah , Department of Management, Marketing and Public Administration .

Anfara, V., and Mertz, N. (2014). Theoretical frameworks in qualitative research. London: SAGE Publications

Baruah, T. D. (2012). Effectiveness of Social Media as a tool of communication and its potential for technology enabled connections: A micro-level study. International Journal of Scientific and Research Publications, 2(5).

Carrington, M., Neville, B., and Whitwell, G. (2014). Lost in translation: Exploring the ethical consumer intentionbehavior gap. Journal of Business Research, 67(1), 2759-2767. http://dx.doi.org/10.1016/j.jbusres.2012.09.022

Castro, J. M. (2006). Relationship Marketing and Consumer Behavior In Fast-Moving Consumer Goods. Universidad of Algarve, Faculty of Economics.

Chauhan, K., \& Pillai, A. (2013). Role of Content Strategy in Social Media Brand Communities: A Case of Higher Education Institutes in India. Journal of Product \& Brand Management, 22(1), 40-51.

Chew, S. S., \& Leng, H. K. (2016). The Role of Social Influence in Purchasing Sports Apparel. Athens Journal of Sports, 3(4).

Euromonitor International. (2017). Sportswear in Saudi Arabia. Retrieved from: http://www.euromonitor.com/sportswear-in-saudi-arabia/report

Gaol, F., Kadry, S., Taylor, M., and Li, P. (2014). Recent trends in social and behaviour sciences. Leiden: CRC Press/Balkema.

(2014) Poverty in consumer culture: towards a transformative social representation, Journal of Marketing Management,30:17-18, 1833-1857, DOI: 10.1080/0267257X.2014.967929

Hamilton, K., Maria G. Piacentini, Emma Banister, Andres Barrios, Christopher P. Blocker, Catherine A. Coleman, Ahmet Ekici, Hélène Gorge, Martina Hutton, Françoise Passerard \& Bige Saatcioglu (2014). Poverty in consumer culture: towards a transformative social representation. Journal of Marketing Management, 30(1718), 1833-1857. http://dx.doi.org/10.1080/0267257x.2014.967929

Hong, I., and Cho, H. (2011). The impact of consumer trust on attitudinal loyalty and purchase intentions in B2C e-marketplaces: Intermediary trust vs. seller trust. International Journal of Information Management, 31(5), 469-479. http://dx.doi.org/10.1016/j.ijinfomgt.2011.02.001

Hoyer, W. D., and Maclnnis, D. J. (2004). Consumer behavior (3rd ed.). MA: Houghton Mifflin Company, Boston.

Kardes, F., Cline, T., \& Cline, M. (2011). Consumer behavior: Science and Practice. South-Western Cengage Learning. .

Khanlari, A. (2015). Strategic customer relationship management in the age of social media. Hershey, Pa.: Business Science Reference.

Lautiainen, T. (2015). Factors affecting consumers' buying decision in the selection of a coffee brand. Saimaa University of Applied Sciences, Faculty of Business Administration.

Lo, L., Lin, S., and Hsu, L. (2016). Motivation for online impulse buying: A two-factor theory perspective. International Journal of Information Management, 36(5), 759-772. http://dx.doi.org/10.1016/j.ijinfomgt.2016.04.012

Makarewicz, A. (2013). Consumer behavior as a fundamental requirement for eff ective operations of companies. Journal of International Studies, 6(1), 103-109.

Mazurek, G., \& Tkaczyk, J. (2016). the impact of the digital world on management and marketing. Kozminski University.

Milano, M., \& Chelladurai, P. (2011). Gross domestic sport product: The size of the sport industry in the United States. Journal of Sport Management, 25(1), 24-35.

Prasath, P., \& Yoganathen, A. (2018). Influence of social media marketing on the consumer buying decisionmaking process. Eastern University, Department of Management. Sri Lanka : SLIS Student Research Journal.

Ravitch, S., and Riggan, M. (2012). Reason and rigor. London: SAGE Publications

Sammut, G., Andreouli, E., Gaskell, G., and Valsiner, J. (2015). The Cambridge handbook of social representations. Cambridge, UK: Cambridge University Press. 
Sokolowski, O. (2011). Influences and attitudes within consumer behaviour process. Place of publication not identified: Grin Verlag Ohg.

Statista. (2015). Total revenue of the global sports apparel market from 2011 to 2018 (in billion US dollars, available at: https://www.statista.com/statistics/254489/total-revenue-of-the-global-sports-apparel-market/.

Taprial, V., \& Kanwar, P. (2012). Understanding social media . bookboon.com.

Tilman, B. (2012). Exploring the reasons why consumers follow a sports brand on social media and the impact this has on brand commitment. Rotterdam: Erasmus University Rotterdam.

Vainikka, B. (2015). Psychological factors influencing consumer behaviour. Bachelor thesis, Gentria university of applied Sciences.

Valentini, C., \& Kruckeberg, D. (2011). New Media versus Social Media: A Conceptualization of their Meanings, Uses and Implications for Public Relations.

Wan, Y. (2009). Comparison-shopping services and agent designs. Hershey, Pa.: IGI Global.

Yang, L., and Mao, M. (2014). Antecedents of online group buying behavior: From price leverage and crowd effect perspectives. Proceedings of 2014 Pacific Conference on Information System (PACIS). Chengdu, China.

Yayli, A., \& Bayram, M. (2012). e-WOM: the effects of online consumer reviews on purchasing decisions. International Journal of Internet Marketing and Advertising, 7(1), 51-64 